\title{
NEW TECHNOLOGIES: GAINS AND LOSSES
}

\author{
Andrea Braun
}

* This paper is a new version of an article published in the Journal Psihoterapija, vol. 31, 2017. In order to distinguish the two papers, I will put in italics the part that has already been printed.

\section{SUMMARY}

This paper is a continuation of an article published in 2017 in the Journal Psihoterapija (vol. 31). Clinical case material from the conference organized by Therapy 2.0 in Zagreb has been added to illustrate limits and opportunities offered by new technologies to our discipline. The author is concerned with how the shift to the virtual dimension as in video sessions via Skype can be helpful or cause damage. The author refers to the experience of being alone in the presence of another (Winnicott) and wonders how the virtual dimension can affect the perception of being safely contained. The importance of body language in a traditional session setting is considered paramount, especially with patients whose suffering is anchored to pre-oedipal phases. The new European laws attach great importance to the protection of privacy but the Snowden revelations in 2013 demonstrated that global digital communications can be easily intercepted. There is an ethical dimension to consider when patients are encouraged to share their most intimate thoughts and fantasies online in a context where it is not possible to guarantee confidentiality of the communication. The author is further concerned with the issue of whether loss is still a core concept in our changing world and in our therapeutic endeavours. She further underlines the importance of carefully evaluating the inherent risks of new technologies in psychotherapy along with the opportunities to broaden outreach.

\section{KEYWORDS}

new technologies, virtual dimension, body language, setting variations, privacy, loss

/ Andrea Braun, psychologyst, psychoanalyst,Private praxis Padova, Italy, IPA member, Mail danaernarub@gmail.com

\section{FLASHBACK}

Let's go back to the 1990s. The Internet is uncharted territory and a new experience for the happy few. My first clinical experience in this field occurs with a patient, Aldo, who had recently returned from Canada, where he had collaborated on a scientific research project at a university. Back in Italy, he was one of the first owners and users of a computer, built and produced in the United States, equipped with software that allowed the use of e-mail. 
I remind you that when Aldo started his analysis, Facebook, Skype, Whatsapp, etc. did not exist. There were no status updates, photos, tweets or video chats.

Aldo wants to start an analysis after he discovers he is attracted to men. He feels hurt by his parents' negative reaction towards his sexual orientation and he suffers social isolation. He knows the lack of contacts and friendships cannot be explained exclusively by the time spent abroad.

Shortly after his coming out, however, an e-mail exchange with Brian, a Canadian colleague, intensifies. Aldo met Brian in the faculty lab just before his departure from Canada. Under the pretext of being sent the data of ongoing research by e-mail, Aldo cultivates their correspondence.

The exchanges with Brian develop entirely through written messages with added acronyms and emoticons.

In analysis it soon becomes evident that their contact through e-mails is sexually charged and addictive.

Every evening Aldo and Brian meet in a "virtual space" by sitting in front of their laptops.

Their e-mail exchanges consist of exciting messages where the two men mutually share their sexual fantasies, which they have never revealed to anyone in "real life".

The technological device replaces phys- space and time. In order to diminish sensorial deprivation, the two men make arrangements like lighting candles or making virtual toasts during the on-line date. Yet, more than vicarious, these expedients seem to underline the role of disembodiment - a fundamental requirement for their relationship. These exchanges are followed by masturbatory discharge.

There are many implications of inhabiting the virtual space we might not have fully considered until later on in the analysis with Aldo.

However, the e-mails make us question the appearance of a new technological medium. In my notes at the time, I record the tendency to consider the e-mails as completely overlapping with other forms of communication. This tendency has been described in literature as "simulation avoidance". Essig $(2015)^{1}$ described the concept: it occurs when practitioners are in denial about the immense technological changes affecting our culture.

So, I imagine that the exchanges between Aldo and Brian, which feed off of absence and take place in a virtual space, can be compared to traditional forms of relationship where letters build a bridge when it is not possible to meet in reality.

At the beginning stage of the exchanges via e-mail, Aldo meticulously describes the content during our sessions. I wonder whether he wants to induce eavesdropping and place the analyst in the role of the excluded third from the primary scene. Had I focused my atten- 
tion on this issue, I would have ended up reinforcing the ongoing "confusion of tongues between the adult and the child", as described by Sandor Ferenzci (1932)2: the exciting atmosphere was supposed to stimulate an unreachable and distant object $^{3}$.

Later in analysis we uncovered the background of Aldo's predilection for new technologies, and we found out it was the vehicle for a need that manifested through negation.

Infantile memories emerged where the patient described his parents' separation when he was still very young. This period coincided with the beginning of kindergarten, the birth of his little brother and his father's abandonment. His mother found it difficult to face all of these changes on her own and she developed a reactive depressive pathology for which she would later seek psychotherapy.

In the face of the dual abandonment (the material departure of his father and his mother's psychic retreat), Aldo described in detail how he would linger for days in front of the washing machine window.

The rhythmic movement and predictable repetition of the wash rotations calmed and consoled him. The washing machine became his shelter, entirely different from the TV where he would be faced with the continuous changing of images. It was essential for Aldo to be able to retreat from the excessive stimulation that arose due to the absence of his caregivers.
In this light, the washing machine offered him containment, which in early childhood had helped Aldo make up for the lack of holding (Winnicott) through physical contact that conveys human affection. His relationship through the PC brought back remote experiences. But thanks to these, we were able to return to early suffering and to foster transformation. It was essential for Aldo to express himself with an analyst who would stay in the background, seldom intervene and help settle the climate of widespread excitement in order that interpretations be given without risk of them becoming further sources of excitement.

The base of the profound psychic transformation my patient underwent seemed to be linked to the experience that Winnicott (1958) 4 defined as being alone in the presence of another. This means being safely contained without being forced to react to or to fulfil any request from the other. It contributed to what Aldo later on in his analysis would describe as feeling real and authentic.

At the time, Aldo often insisted on telephone sessions when he had to work out of town, which I refused. More than 20 years later, I now ask myself how his treatment would have developed if I had accepted, or if we had had access to technology such as voice or video sessions. Would it have been possible to sustain his development without falling into the trap of an exciting verbal exchange rather than focusing on his need for infantile language and body presence? 
During the final phase of Aldo's treatment, while expressing gratitude for his achievements, he jokingly observes that nobody besides us will be able to understand how, in the first part of his treatment, he simply needed an analyst capable of functioning like the silent and slow washing machine of his childhood. Only this way could he recover the painful memories of the past that he would have to work through in order to tolerate emotions and changes in life. His sense of humour and a capacity for play testify to Aldo's discovery of a transitional space that helped him to attain an affective dimension that was sufficiently rewarding in order to allow for a stable domestic relationship with a partner.

\section{NEW TECHNOLOGIES}

In 1997, which falls within the period of Aldo's analysis, Stratton (in Lemma A., 2015)5 described cyberspace as "the space produced by human communication when mediated by technology in which the body is absent". Nearly twenty years later, at the $49^{\text {th }}$ meeting of the IPA in Boston 2015 - Psychoanalysis in a Changing World, the focus was on the transformations that new technologies have brought about in our work as psychotherapists and psychoanalysts.

One of the clearest ideas that emerged was the importance of rethinking certain axioms that lie at the foundation of our professional identity, such as the importance of neutrality and abstinence (Freud, 1913-1914)6, while bearing in mind the impact the alteration of privacy has on our profession.

In clinical work, for example, we quite often find that before patients arrive for their first interview, they have already done an online search where they discover not only our $\mathrm{CV}$, but also the professional and personal interests of their future therapist.

Once therapy has begun, these patients try (and often) succeed in tracking our movements and habits using a variety of online resources. Safeguarding our intimacy in the face of these intrusions becomes a challenge. For example, we find it hard to believe, but simply owning a modern smartphone allows patients to know exactly when we access chats in Whatsapp, Telegram, Viber, etc.

At the extreme ends of this evolution we have technologically mediated treatment, which sets aside physical presence in a shared space and opts for the use of software like Skype or telephone communication. The level of spread of this kind of treatment is quite high in certain contexts. In fact, results from a questionnaire from the British Psychoanalytical Society show that $31 \%$ of participating members have experience doing analysis via Skype or telephone (Fornari-Spoto 2011, cit. by Lemma and Caparrotta 2014, 1) ${ }^{7}$.

In light of this, we believe it is important to take a deeper look at the disap- 
pearance of the body in this new set-up, which deprives us of the familiar dimension of two people speaking together in a room (Nissim Momigliano, 1984) ${ }^{8}$.

Are we truly convinced by Scharff (2010, 990) ${ }^{9}$ when he claims that "psychoanalysis is mainly the encounter with an understanding mind in whatever setting that may occur" and that physical presence is a marginal element? I find myself leaning towards those who believe that, however limited direct physical contact might be between a therapist and a patient in the talking cure, the potential to evoke that contact and the desire to establish it contribute to the experience of transference and add to the tension within the relationship (cfr. Sabbadini, 2014) ${ }^{10}$. Almost a century has passed since Freud (1922) ${ }^{11}$ stated: "the Ego is above all a corporeal ego". This discovery has significantly influenced the psychoanalytic approach, although the translation of the Freudian text itself has led to certain misunderstandings. For example, Bettelheim ${ }^{12}$ reminded us how "Seele" in German (soul in English) changed into the term "mind" in the English version of the Standard Edition. Perhaps this semantic shift has conditioned the kind of orientation that we find in Scharff's claim (ibid.). Although psychoanalysis has considered the talking cure from the outset, where one seeks to achieve transformations through verbal interpretations, Freud $(1905)^{13}$ himself paid a lot of attention to body language. This can be seen, for example, in the case material concerning
Dora in the passage where he considers the importance of masturbation in his patient's life and in the formation of her symptoms. He describes the patient lying on the couch and playing with a small reticule by moving her finger in and out.

We must carefully consider the role of body language in candidate training. We run the risk of underestimating the importance of it, especially in patients where suffering is anchored to pre-oedipal phases. Furthermore, we have to distinguish between the tendency to somatise and a conversion symptom. The former speaks of very early suffering that was unable to reach a psychic level.

Requests to carry out sessions via Skype do not always arise from practical necessity, such as the need for greater mobility required by the job market. It is necessary to closely analyse the resistances that accompany every proposal for a change in the setting. In my experience, such a request came about surprisingly at the end of an analysis. It seemed to stem from the wish to keep the relationship open rather than facing the eventual separation from the therapist. My interpretation of this fantasy that things are 'never-ending', because there is always the potential for connection, which although virtual is nonetheless always possible, allowed us to examine the question and marked the concluding phase of the treatment. This doesn't mean that there aren't good reasons to consider these kinds of requests, but we must be aware of what can be lost. 


\section{PRIVACY}

Nonetheless, working with modern systems of telecommunication carries certain implications regarding the protection of confidentiality and privacy in our studios. At the Annual Conference of the EPF in Stockholm in 2015, Churche ${ }^{14}$ clearly underlined how, following the Snowden revelations in 2013, it had become impossible to ignore the routine practice of wiretapping and interceptions in global digital communications, Skype among them. Churcher recalls that the act of large-scale communications interception had already been documented in an in-depth report by the German weekly journal Der Spiegel. This report explicitly mentions Skype, which turns out to be the most commonly used program in online analysis and psychotherapy. In order to carry out videocalls, this program makes use of a VoIP protocol and the data is coded. This did not impede the NSA from heavily intercepting Skype conversations since 2011. The recent scandals (Facebook and Cambridge Analytica) made us recognize that we as analysts should wonder about the risks to which we expose ourselves and our patients when we agree to conduct psychotherapeutic treatments online. What right do we have to encourage our patients to share their most intimate thoughts and fantasies with us when we are unable to guarantee the confidentiality of communication. This contradiction falls onto us because we are ethically responsible.

\section{IS LOSS STILL A CORE CONCEPT?}

Patients aren't the only ones who make extensive use of new technologies; although we don't belong to the 'head down generation' of the millennials, we do our fair share with the connected world. The computers in our studios usually stay on throughout the day and we often take a quick look at our inboxes between one patient and another. Who among us hasn't considered this behaviour a subtle form of addiction?

New technologies imply the guarantee that the object is always reachable. This object is accompanied by the absence of space, time and bodily limits, which can alter the capacity to work through loss, separation, grief, and interfere with the ability to tolerate anticipation, waiting, ambiguity and doubt. All these elements lie at the origin of creativity, and they do not easily reconcile with today's common expectations of getting the kind of readymade and immediate answers found online.

According to Guignard (2014)15, psychic organization has suffered certain changes due to the introduction of virtual communication, especially in connection with the developmental age. Among the risks reported we find the weakening of the boundaries between external and internal reality, between the real and the digital. This might have contributed to an increase in the number of borderline states at the expense of neurotic pathology, which prevailed in the last century. 
Matačić (2014)16 would call our attention to the evolution of language and the creation of new oxymorons. The term "virtual reality" is particularly striking as it highlights just how the boundaries between the two planes are dissolving.

Guignard pinpoints another problem for psychoanalysts when she talks about the prevalence of images and perception in the digital universe to the detriment of the importance we are used to attributing to representation and language. The images we find on the net are prefabricated and don't require further elaboration, such as in interactive games on video game consoles that capture children's interest. In these games, children are required to improve their hand-eye coordination and control through quick movements of the cursor. Rapid movements are rewarded and lead to success and therefore narcissistic reinforcement. Within these videogames, it is hard to recognize the element of "play" that refers to Winnicott's transitional space. Guignard goes on to mention other harmful features such as the damage caused to the concept of friendship. The number of "friendships" we have in our Facebook accounts has little to do with the concept of true friendship, which needs to be fostered through the investment of time, interaction, affects and thoughts etc.: connection is the goal and quality does not matter.

The internet's expansion forces us to reflect on how we, as psychoanalysts and psychotherapists, deal with our instru- ments in a context that is more and more oriented towards other forms of reality (such as Matačic's oxymoron) in contrast to those we commonly share.

As in Winnicott's theory, the infant reaches reality only after the environment succeeds in providing the illusion of omnipotence ("the breast is mine") at the beginning of his life. On this ground, the infant will be able to tolerate the gradual disillusion triggered by the inevitable frustrations until he is able to accept reality with its limits. The experience of having had the mother, of having lost her, and having been able to recreate her is the triad that allows the infant to gain access to a potential space where it is possible to be creative and authentic.

Once more, the emphasis is on the importance of working through a loss (the mother). With his concept of transitional space, Winnicott enriches Freud's concept of the reality principle and the role played by the Ego. According to Freud, in order to obtain satisfaction, this agent in the psychic apparatus has to evaluate whether it is possible to act immediately or if it is necessary to postpone or even abandon gratification completely so as not to expose oneself to danger. ${ }^{17}$

The digital universe affects the limits imposed by reality and contributes to changes in our mental functioning. Sonia, a 53-year-old woman, turns herself into 20-year-old Marco in chats. Here she experiments with the possibility of overcoming the biological limits imposed by 
her gender identity and actual age. In certain cases, this ends up determining "the disengagement from external reality and the hyperinvestment in the technological fetish that replaces it" (Biondo 2016, my translation) ${ }^{18}$.

For a less dramatic view than Guignard's, we might turn to Alessandra Lemma's (2015) paper in Boston. Lemma does not share the tendency to see the virtual and the real as overlapping, but rather considers them complementary. This doesn't mean belittling the virtual as an inauthentic experience, but rather to grasp its potential and its risks.

One of the features of cyberspace regards the possibility to experiment with different representations of the self. As Sonia shows us, whoever surfs the web can easily change his or her identity by simply switching avatars in chat rooms, forums or online games. This embodiment allows us to widen the boundaries imposed on us by our bodies and distance ourselves from organic nature (see Caparotta L.; Lemma A. 2014). These are experiences where physical reality can, at least partially, be replaced by the virtual.

Let me give you some clinical material: Anna began psychotherapy two years ago with once-a-week sessions because she had been unable to return to independent living after her husband walked out on her. She feels stuck and wonders "when will it finally be again as it has never been before?" Her addiction to the Internet plays an important role in this situation, which manifests in a compulsion to check her ex-husband's Facebook page multiple times a day.

During the course of therapy and through the therapeutic relationship, she is gradually able to invest in reality and moderate her need for this form of control, which was intended to stop time. She slowly realizes that she has been clinging to an online fiction that has resulted in her giving up on her own life. I'd like to present some material from a session that took place at the end of the second year of therapy.

The associations start with Anna remembering Marsha, a medical doctor and a friend who had passed away at the beginning of the previous spring from liver disease. Anna misses her friend deeply. She tells me just before coming to the session she had received a notification from Marsha's Facebook account. When she opened the page, she saw a photo of Marsha in her white doctor's coat. How is it possible, she wonders, since Marsha passed away more than a year ago. Only afterwards did she see the date: "January 2015". So, on that date Marsha was still alive, working in a hospital, but who was sending her photos from this account now? Is there somebody who gets hold of our social media accounts after death?

Then Anna begins to ask herself about the difference between the past and the present. She refers to the present as being conditioned by the Net. She remembers the death of her grandmother when she 
was an adolescent. She used to go to the cemetery and stand in front of the grave. You could have a conversation with the dead, a one-way conversation, she stated, but Anna still felt like her grandmother was there to hear what she had to say.

Anna is persuaded that something substantially different occurs nowadays and new forms of technology pick up ancient rituals. Facebook connects us to broader groups of people, and there is a group interaction that behaves as if there were still a person able to really exchange messages with all of us.

For Anna, the fetish dimension manifests itself through the substitution of her painful solitude with her addiction to Facebook. In her case, the social network feeds her illusion that her ex-husband is still receptive and continues a relationship with her in her daily life.

She says that it would be easier if he were really dead, but he is not.

Anna needed a setting that was significantly different from sitting alone in front of a computer. A setting which sets forth a virtual temporal space - where every session is interrupted after 45 minutes, where presence and absence are clearly defined. In this way, Anna is able to slowly scale back the illusion of being able to exercise control over her ex-husband and come to terms with the separation that had occurred.

I believe this example, more than any of the other ones, helps us face these rad- ical changes. In Black Mirror, a British TV series, that takes place in a familiar future, the spectator comes face to face with the challenges that the evolution of new technologies brings. One of the episodes, "Be Right Back", revolves around the question "who are we?".

A young woman anxiously awaits her husband's return home. He is late, and he does not answer her calls. He appears "offline". The arrival of a police car confirms her anguish. We understand from the scene that her husband has died in an automobile accident.

During the funeral, the window is approached by a close friend who also experienced loss. The friend suggests she open an account and download an application that will help her grieve.

The initial refusal to seek help online changes once she discovers she is pregnant. She installs the app, which grants her access to a disquieting reality. The software carries out a scan of all of her husband's online history and the result is a profile/avatar capable of interacting with her as if her husband was still alive. Through the app, the couple chat and speak on the phone. It is disquieting how "faithfully" the program is able to reproduce the original.

For a psychoanalyst, reality "defined by loss is rapidly being supplanted by something new" that we can define as "infinite access", up to the point that we realize that "loss is lost" (Hartman 2011) 
But sometimes turning to our technological tools can prove helpful in the therapeutic process. I found this in my work with Mario, where the possibility to get in touch with one another between sessions by text message played an important role in the elaboration of separation.

Mario is a young adult I've seen for seven years in psychotherapy. Treatment began after he was referred to me by his paediatrician due to a serious phobic symptomatology when he was an adolescent. We started out with once-a-week sessions and gradually arrived at three times a week.

After six years we came to a difficult moment.

Mario graduated from high school and enrolled in his first year in the faculty of medicine. In his fantasy, this would have meant never having to separate from me, because we would share a similar profession. He wanted to become a psychiatrist.

While preparing for an exam involving autism just before the summer break, Mario came across Bruno Bettelheim's book (1967)20 entitled "The Empty Fortress". In many of our sessions, he talks about the autistic pathology of the patients described in the book. He recognizes himself in their suffering and feels desperation for what he sees at the core of their existence: emptiness. Mario fears that he doesn't have the resources needed to cross this "desert".

Bettelheim's topic becomes the subject of carefully considers the vicissitudes of a child described in the book. After making considerable progress, this patient's parents pull her out of the orthogenetic institute where she was being treated for serious emotional disturbances. Following the disruption in her therapy, she ends up developing a severe regression and is never able to recover.

At the same time, Mario discovers that he can transmit his anxieties to me through text messages. These become a bridge during weekends and days when we don't see each other. I respond as little as possible to his messages, but I ask him to read them at the beginning of each following session, so they become a part of our work together and we avoid creating an area of splitting.

A few days prior to a long holiday all of Mario's desperation emerges.

His text messages increase in number, and threats of suicide begin to appear.

In the end, Mario sends me a text saying that he has tried to commit suicide. He then immediately calls me on his cell phone and tells me he has swallowed paracetamol painkillers. I am able to convince him to tell me where he is, I reach him and take him to the emergency room just in time.

Once we restart therapy, Mario conveys how important it was to feel that his life was important to me and that I was willing to go out of my way for him. 
Those text messages were an important vehicle that allowed Mario to become aware of the pain of separation, which he had always denied in the past. That pain culminated in a dramatic episode, and we were fortunate to handle it in time.

It was touching to hear the description of the thoughts that went through Mario's mind after he had taken those pills. He thought that passing beyond - to the kingdom of the dead - would have exposed him to an immeasurable solitude, whereas he was certain that if he reached out for me, I would answer his call and stand by his side.

A year later, during the summer break, I received a text from Mario. He began by apologizing for disturbing me, but he wanted to tell me he had changed faculties, no longer studying medicine but engineering, and was going to move to a city nearby so he could continue his therapy. He wanted to let me know that we would have to find a new timetable because of the changes, but said he was sure we could sort things out once I returned from my holidays. He ended by wishing me a good vacation.

Just like our patients we are faced with the difficulty in keeping pace with the changes that our transforming world forces on us. That being said, if we don't want to miss the opportunity to make creative use of these new forms of technology, we have to safeguard our curiosity. We must wonder about the influences that those new forms have on all of us, and whether they lead towards enrichment or deprivation.

If we're not careful, we'll end up chasing nostalgia for the past.

\section{REFERENCES}

1. Essig T. (2015). The gains and losses of 'screen relations': a clinical approach to simulation entrapment and simulation avoidance in a case of excessive internet pornography use. Contemporary psychoanalysis, 51 (3).

2. Ferenczi, S. (1949). Confusion of tongues between the adult and the child (The language of tenderness and of passion). Int. J. Psycho-Anal., 30: 225-30.

3. In countertransference I had the impression that Aldo was trying to create an exciting atmosphere in order to stimulate a depressed mother.

4. Winnicott D.W. (1958). The capacity to be alone. International Journal of Psychoanalysis, 39: 416-420.

5. Lemma A. (2015). La psicoanalisi ai tempi della tecnocultura: alcune riflessioni sul destino del corpo nello spazio virtuale. Rivista Psicoanal., 61: 457-476. The title of the original keynote paper in Boston: "Psychoanalysis in times of technoculture: Some reflections on the fate of the body in virtual space".

6. Freud S. (1913). On Beginning the Treatment (Further Recommendations on the Technique of Psycho-Analysis I). S.E., 12. London, Hogarth.

7. Caparrotta L., Lemma A. (2014) Introduction. In: Psychoanalysis in the technoculture era (Lemma A., Caparrotta L., edited by). East Sussex, New York, Routledge. 
8. Nissim Momigliano L. (1984). "... Due persone che parlano in una stanza ..." (Una ricerca sul dialogo analitico) (*). Rivista Psicoanal, 30: 1-17.

9. Scharff J.S. (2010). Telephone Analysis. Int. J. Psycho-Anal., 91: 989-992.

10. Sabbadini A. (2014). New technologies and the psychoanalytic setting. In: Psychoanalysis in the technoculture era (Lemma A., Caparrotta L., edited by). East Sussex, New York, Routledge.

11. Freud S. (1923). The Ego and the Id. S.E., 19. London, Hogarth.

12. Bettelheim B. (1982). Freud and man's soul. New York, Alfred A. Knopf, Inc

13. Freud S. (1905). Fragment of an Analysis of a Case of Hysteria. S.E., 7. London, Hogarth.

14. John Churcher J. (2015). Privacy, Telecommunications and the Psychoanalytic Setting. In: EPF Bulletin 69, 221-233.

15. Guignard F. (2014). Psychic development in a virtual world. In: Psychoanalysis in the technoculture era (Lemma A., Caparrotta L., a cura di). East Sussex, New York, Routledge.

16. Matačić S. (2014). Psihoanaliza i naše doba. In: Klein E. (a cura di) O psihoanalizi sasvim otvoreno Školska knjiga, Zagreb, 73-93.

17. Freud S. (1938). An Outline of Psycho-Analysis. S.E., 23. London, Hogarth.

18. Biondo D. (2016). Nuove tecnologie e dolore psichico. Paper presented in Padova, CVP in aprile 2016.

19. Hartman S. (2011). Reality 2.0: When Loss Is Lost. Psychoanal. Dial., 21(4): 468-482

20. Bettelheim B. (1967). The empty fortress. New York, Free Press. 